\title{
Training Psychiatry Residents in Descriptive Psychopathology: A Systematic Review
}

\author{
Jon-Inaki Etxeandia-Praderaa, b, c Daniel Martinez-Uribe ${ }^{c, d}$ \\ Francisco Bellver-Pradas ${ }^{a}$ Jose-Carlos Gonzalez-Piqueras ${ }^{a}$, b, c, e \\ Juan Nacherb, e, f Eduardo-Jesus Aguilar a, b, c, e
}

${ }^{a}$ Hospital Clínico Universitario de Valencia, Valencia, Spain; ${ }^{\text {b}}$ Hundación Investigación Hospital Clínico de Valencia, INCLIVA, Valencia, Spain; 'Department of Medicine, University of Valencia, Valencia, Spain; dUnitat de Salut Mental I'Hospitalet, Institut Català de la Salut, L'Hospitalet de Llobregat, Spain; ${ }^{\circ}$ CIBERSAM: Spanish National Network for

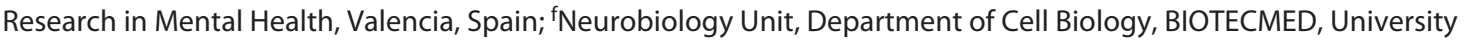
of Valencia, Valencia, Spain

\section{Keywords}

Descriptive psychopathology · Training · Psychiatry

residents · Mental symptoms · Medical education

\begin{abstract}
Purpose: Descriptive psychopathology (DP, sometimes called psychopathology or phenomenology) is the language of psychiatry and is dedicated to the description of mental symptoms. Due to its importance, there is an ongoing case to put it back at the heart of psychiatry and its training. This study seeks to examine the literature on how to train psychiatry residents in DP, including reported educational interventions and educational methods. Method: The authors conducted a systematic review following the PRISMA and BEME guidelines to identify literature on how to train psychiatry residents in DP. In May 2019, they searched in Embase, ERIC, PsycINFO, PubMed, Scopus, and Web of Science; of 7,199 initial results, 26 sources were finally included for analysis. The assessment tools were the CRAAP test, Kirkpat-
\end{abstract}

rick's 4 levels, and (when applicable) the Medical Education Research Study Quality Instrument (MERSQI). Results: The mean CRAAP score was 38.885 of a possible 50 (SD 0.983; range: $36.859-40.910)$. Fourteen sources (53.8\%) had some kind of training evaluation: Kirkpatrick's level 1 was present in nearly all (13) and was the highest in half of them (7). Regarding the educational interventions, the mean MERSQI score was 10.592 of a possible 18 (SD 2.371; range 9.08512.098). Lectures were the most widely reported educational method (5); among those in clinical settings, the live supervised interview with feedback was the most usual (4). Conclusions: Despite its core importance as the language of psychiatry, the literature about training psychiatry residents in DP is scarce and heterogeneous. General lack of training evaluation and ongoing overemphasis on Kirkpatrick's levels 1-2 at the expense of levels 3-4 are causes for concern. During the review process, the authors identified a selection of educational interventions that could serve as the basis for the design of new training efforts in both clinical and nonclinical settings. Topics for future research are also suggest-

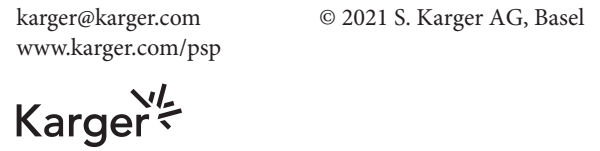

Jon-Inaki Etxeandia-Pradera 
ed, such as the role of DP in competency-based training frameworks now in vogue and a series of neglected contents. Finally, the combined use of the CRAAP test and the MERSQI may be useful for future systematic reviews in medical education.

(c) 2021 S. Karger AG, Basel

\section{Introduction}

Psychiatry is the branch of medicine focused on the diagnosis, treatment, and prevention of mental, emotional, and behavioral disorders [1]. Descriptive psychopathology (DP, sometimes called psychopathology or phenomenology) is the language of psychiatry, a systematic collection of assumptions, vocabularies, and grammatical and syntactic rules which is dedicated to the description of mental symptoms [2].

\section{DP: History and Epistemology}

Psychiatry emerged in Europe in the wake of the 19th century as a medical approach to madness, following social and legal changes across several countries at the time. Those early psychiatrists (alienists) needed to record what happened to their patients, so they had to create a psychopathological language to capture in words that phenomena and construct units of analysis. Pinel's 4 categories of mental alienation were broken up into fragments, some of which were to be reconstructed as mental symptoms [3].

This development of DP was conducted in the image of the semiology of medicine (itself based on the anatomoclinical model) and influenced by psychological theories then in vogue (such as associationism and faculty psychology). As a language, DP was practically completed when Chaslin and Jaspers published their texts in the 1910s; it has remained stable since then, so the current DP we use nowadays still keeps conceptual views of those days [4].

Mental symptoms, as the units of analysis of DP, include subjective complaints (e.g., feeling anxious and hearing voices) and signs and behaviors determined through observation or instruments (e.g., delusions, psychomotor retardation, cognitive deficits, and disinhibition) [5]. The Cambridge School of Epistemology and Psychopathology led by Professor Berrios states that mental symptoms are genuine actions, through which a distressful experience (of either biological or semantic origin) is configured by means of personal, social, and cultural templates, first by the patient himself/herself and then through a hermeneutic process by the clinician who will record it in the casenotes [6].

Thus, in historical and epistemological terms, psychiatry and its language (DP) are rooted in both the natural and social sciences [7]. The objects of inquiry, mental symptoms, are neither natural nor abstract objects; they are hybrid objects, constituted by the blending of components arising from disparate sources of knowledge as they combine biological and cultural information [8].

\section{The Importance of DP}

It has been argued that at present, mental symptoms play a more important epistemological role in psychiatry than medical symptoms in medicine, as medical symptoms are being gradually replaced by "biological" markers [5]. In contrast, psychiatry remains dependent on mental symptoms for diagnosis, treatment decision-making, evolution assessments, research, etc. Just as pointed by Fish half a century ago [9], the need for careful description of clinical phenomena in psychiatry is greater than ever before.

DP has faced strong pressure in recent decades from classification systems such as the Diagnostic and Statistical Manual of Mental Disorders (DSM) of the American Psychiatric Association, which has a neopositivist-analytic orientation and gives preference to observable external behavior while subjective experience is for the most part dismissed. DSM assumes mental symptoms as well-demarcated, mutually independent, natural objects with no intrinsic meaning and indicative of a specific physiological dysfunction. In this view, mental symptoms are thinglike objects waiting to be grasped, so they are open to context-independent operational definitions and can be unproblematically registered and quantified. Following this rationale, the structured interview and subsequent checklists mimicking the operational diagnostic criteria of DSM are widely regarded as adequate methods of obtaining valuable information. The process of collecting data is done by circumventing or shortcutting the complexities of subjectivity and intersubjectivity in the patient-clinician exchange [10-13].

In essence, DSM and its associated mainstream psychiatry have failed to acknowledge mental symptoms as admixtures of biological and sociocultural components (hybrid objects) that are co-constructed by both the patient and the clinician. This failure in understanding the basics of DP has come at a cost to psychiatry. In the field of assessment and diagnosis, procrustean errors (to stretch and trim the patient's experience to fit operational criteria) and tunnel vision (avoiding the assessment of 
phenomena not included in standardized interviews) have sadly become common practice [14]. On behalf of interrater diagnostic reliability, validity has been sacrificed, and treatment decisions and research are made without a proper psychopathological assessment $[15,16]$, which may jeopardize patients' prognosis.

Moreover, the misguided assumption of mental symptoms as thing-like objects that can be located in time and space in the brain and can guide us toward their biological causes, without realizing that they are hybrid objects with varying degrees of brain inscription, has led to an increasing gap between psychiatry research and clinical psychiatry [11-13]. For decades, most research efforts have tried to establish correlations between alleged mental symptoms and neuroscience findings (e.g., neuroimaging). This hegemonic yet ill-fated approach has failed to produce real benefits for patients; it is also impeding the development of a flexible and conceptually sophisticated psychiatry [10]. The new Research Domain Criteria (RDoC) project developed by the US National Institute of Mental Health considers mental disorders as "disorders of brain circuits" [17], arguably misleading brain mediation/inscription with etiology. Due to its dismissal of the basics of DP and its overemphasis on biological over psychosocial variables, $\mathrm{RDoC}$ may well be conceptually flawed as well [18-22].

Nevertheless, the most costly of the consequences for psychiatry has been dehumanization: as a true dialogue between interviewer and interviewee has been discouraged and the patient qua person and the clinical encounter have been dehumanized $[14,15]$. This is particularly painful and troubling for psychiatry because as pointed by Berrios [23], patients are its only raison d'être. DP, due to its properties [24], is the guarantee that psychiatry stays rooted in the patient and the patient-clinician encounter.

\section{The Case for Training in DP}

DP is said to be neglected in contemporary training in psychiatry [25]. As psychiatric textbooks limited their psychopathological section to reprinting operational diagnostic criteria [13], DSM became the basis for psychiatric teaching to both residents and undergraduates. Over the last several decades, there has been a substantial decline in training in careful clinical assessment targeted to the individual person's problems and social context [15].

This is critical, as cultural configurators from both the patient and the clinician (background, education/ training, experience, and personal biases) contribute to the way in which a distressful experience is identified, interpreted, and named as one or more mental symp-

Training in Descriptive Psychopathology toms [10]. While detailed history taking has been replaced by structured psychometric scales, a magnificent thesaurus of psychopathological knowledge and indepth, fine-grained descriptions has been removed from psychiatric educational programs [14]. Failing to train in the knowledge, skills, attitudes, and clinical use of DP implies psychiatry mortgaging its own identity and future [25].

Amidst this climate, there is a case to be made to rediscover and highlight the relevance of DP, thereby putting it back at the heart of psychiatry and its training [16, 2628]. It has been stated that DP should be a basic educational prerequisite in the curriculum for mental health professionals [24]. Also, training in DP should be implemented with innovative instruments and approaches within psychiatric curricula [25].

Hopefully, well-trained and aware 21st-century psychiatrists will take part in the recalibration of DP in order to have a language that lives up to this century. By doing so, they will engage in the objective of having a psychiatric language in the best interest of patients, either for clinical practice or research [29].

\section{Training Psychiatry Residents in the 21st Century}

In a world in constant change and full of uncertainties that have a direct impact on health systems, society demands health professionals (e.g., psychiatrists) who are flexible in adapting to the new times and challenges [30]. Despite some differences between countries, becoming a psychiatrist usually involves 2 consecutive phases: undergraduate medical education (medical school) and postgraduate medical education (psychiatry training or residency) [31]. Psychiatry residency is essential for the psychiatrists of the future (who may have clinical, managerial, educational, and research duties) [32], as it provides them not only the tools (knowledge, skills, and attitudes), but also real-life scenarios (with actual patients, families, colleagues, managers, and resources) to put them into practice.

As pointed by Kirkpatrick and Kirkpatrick [33], there are 3 major reasons to evaluate training programs: (1) to improve the programs, (2) to maximize transfer of learning to behavior and subsequent results, and (3) to demonstrate the value of training to the stakeholders (accountability). In the field of medical education, evaluation and research of educational efforts are considered essential to learn what has worked or not. Evaluation and research are also important in order to construct an evidence based on best practice that can be disseminated and adapted to improve training worldwide [34]. 
Table 1. Inclusion and exclusion criteria

Inclusion criteria for the systematic review

Educational interventions in DP for psychiatry residents that describe the contents included and the educational methods employed

Educational interventions for psychiatry residents that include training in DP and describe the contents included and the educational methods employed

Reviews on educational interventions in DP for psychiatry residents

Studies that evaluate training in DP for psychiatry residents

Studies regarding the assessment of training in DP by either psychiatry residents or trainers

Reviews on educational methods employed in educational interventions in DP for psychiatry residents

Articles and book chapters that reflect on the design and educational methods of educational interventions in DP for psychiatry residents

Exclusion criteria for the systematic review

Studies that are neither in English nor Spanish

Letters to the editor

Book reviews

Articles regarding educational interventions for undergraduate students

Articles regarding educational interventions for residents or specialists of other areas (general practice, neurology, clinical psychology, and mental health nursery)

Articles regarding educational interventions for psychiatrists who are already specialists

Articles regarding educational interventions focused on training in other areas (psychodynamic psychopathology, nosology, psychopharmacology, psychotherapy, electroconvulsive therapy, and neurobiology)

Proposals or reflections on training in DP that do not develop an intervention program or that do not disclose an educational method

DP, descriptive psychopathology.

Training in psychiatry and other medical specialties is undergoing the transition from opinion-based education to evidence-based education [35]. In this sense, a systematic review is an explicit, rigorous, and transparent process of searching, selecting, appraising, interpreting, and summarizing results from published studies on a specific topic. In contrast, traditional literature reviews are not so rigorous regarding their methods and are susceptible to selection bias, preventing the presentation of a broader view. Thus, systematic reviews are an important tool for professional educators who seek the best available evidence to inform their actions, and they are recognized as such among other institutions by the Best Evidence Medical Education (BEME) Collaboration and the Association for Medical Education in Europe [36-39].

\section{Research Objectives}

As there is an argument for ensuring that DP is at the heart of psychiatry and its training, we decided to conduct a systematic review to examine the literature on how to train psychiatry residents in DP. Our secondary objective was to know what educational interventions have been reported in these publications for training psychiatry residents in DP, as well as the educational methods involved.

\section{Methods}

We conducted a systematic review following the PRISMA guidelines and also considered recommendations by BEME guidelines $[36-38,40]$.

\section{Identifying the Literature}

Once we had developed the idea, we set the inclusion and exclusion criteria (Table 1). Then, we constructed the search syntax: "phenomenology/education," "phenomenology AND (education OR pedagogy OR teaching OR training) AND (residen* OR intern* OR trainee)," "psychopathology/education," and "psychopathology AND (education OR pedagogy OR teaching OR training) AND (residen* OR intern* OR trainee)."

Based on already known recommendations [41], as well as our research question and topic, we selected the following databases: Embase, ERIC, PsycINFO, PubMed, Scopus, and Web of Science.
Etxeandia-Pradera et al. 
We conducted the search from May to June 2019, and the 4 previously detailed search syntax yielded 1,041, 1,591, 81, and 4,473 studies, respectively. Besides these 7,186 results coming from databases, we also included 13 studies from the gray literature for consideration, for a total of 7,199 search results.

Using the Mendeley Reference Manager, 970 results were automatically identified as double hits, leaving us with 6,229 results for manual screening using the previously set inclusion and exclusion criteria. We dismissed 6,013 because of the title, 134 because of the abstract, and 53 after having read the full text. As for the remaining 29 results, 3 were parts of the same paper [42-44], whereas 2 corresponded to different but nearly identical editions of the same book chapter $[45,46]$; this left us 26 sources for the review. The whole process is summarized in a flow diagram (Fig. 1).

\section{Assessment Tools}

Based on already known recommendations [47], we decided to use the CRAAP test, Kirkpatrick's 4 levels, and the MERSQI as assessment tools for this review. The CRAAP test evaluates 5 domains to rate a source: currency, relevance, authority, accuracy, and purpose. Used by librarians around the world, it can be converted into a numerical scale, and it has already been used in articles of medical journals for that purpose [48]. We followed the model adapted by the librarians of the Texas State University, which proposes to evaluate each domain at $0-10$ points, giving a total score of $0-50$ points with different levels: excellent (45-50), good (40-44), average (35-39), acceptable (30-34), or unacceptable $(<30)[49]$.

Kirkpatrick's 4 levels are arguably the most widely used training evaluation model in the world. It consists of level 1 or reaction (the degree to which participants find the training favorable, engaging, and relevant to their jobs), level 2 or learning (the degree to which participants acquire the intended knowledge, skills, attitude, confidence, and commitment based on their participation in the training), level 3 or behavior (the degree to which participants apply what they learned during training when they are back on the job), and level 4 or results (the degree to which targeted outcomes occur as a result of the training and the support and accountability package) [33].

The MERSQI (Medical Education Research Study Quality Instrument) assesses the methodological quality of published medical education research reports on 10 items clustered in 6 domains: study design, sampling method (number of institutions involved and response rate), type of data, validity of evaluation instrument (content, internal structure, and relationship to other variables), data analysis (sophistication and appropriateness), and outcomes. The total score of any intervention has a range of 5-18, with higher scores reflecting more rigorous studies; the instrument has been reviewed as a useful and reliable tool [50].

\section{Data Extraction and Assessment}

We conducted data extraction and assessment from July to September 2019. From every source, we took its first author, publication year, and country. We specified what type of source it was, and we wrote a brief summary of it. In order to assess each source's appropriateness regarding the research question and its level of training evaluation, we used the CRAAP test and Kirkpatrick's 4 levels, respectively.

Those sources that included an educational intervention with some kind of training evaluation (Kirkpatrick's level 1 or higher)

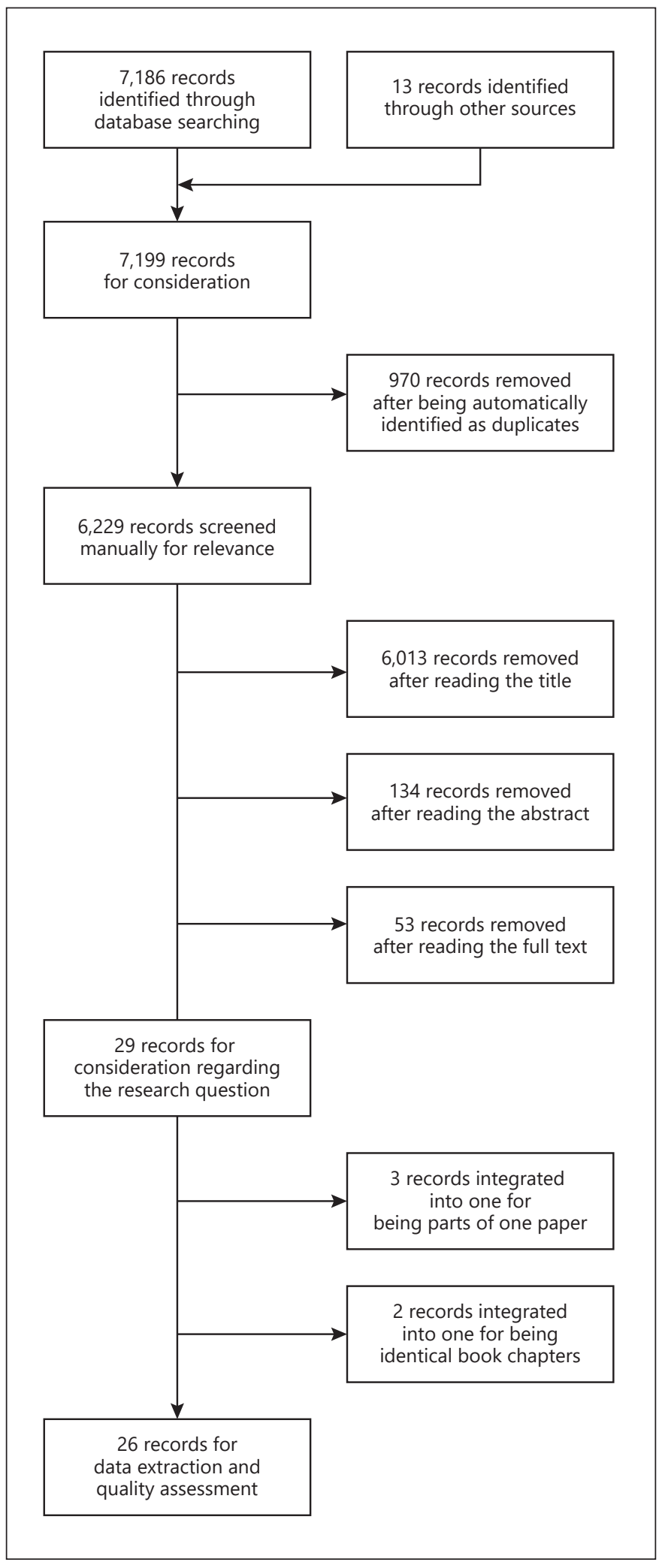

Fig. 1. Flow diagram 
Table 2. Description of 26 studies of training PR in DP, including their appropriateness (CRAAP test) and training evaluation (Kirkpatrick's levels)

\begin{tabular}{|c|c|c|c|c|c|}
\hline Source & Country & Type & Summary & CRAAP & Kirkpatrick \\
\hline Blass [61] & USA & Framework proposal & $\begin{array}{l}\text { A framework for teaching PR how to deal with religious patients, } \\
\text { including issues regarding psychopathology and assessment }\end{array}$ & 33 & - \\
\hline Brenner [62] & USA & Literature review & $\begin{array}{l}\text { Use of simulated patients has intrinsic limitations in psychiatric } \\
\text { education, specially regarding empathy and interpersonal relationship }\end{array}$ & 40.5 & - \\
\hline $\begin{array}{l}\text { Bromley and Braslow } \\
\text { [63] }\end{array}$ & USA & Course design & $\begin{array}{l}\text { Highlight relevance of sociocultural context in psychopathology, } \\
\text { incorporating social sciences to PR's curriculum through } 4 \text { modules }\end{array}$ & 43 & - \\
\hline $\begin{array}{l}\text { Etkin and Cuthbert } \\
\text { [69] }\end{array}$ & USA & Course & $\begin{array}{l}\text { Transdiagnostic neuroscience course consisting of weekly lectures about } \\
\text { topics closely aligned with the RDoC }\end{array}$ & 33.5 & 1 \\
\hline Fiorillo et al. [70] & Europe & Survey & $\begin{array}{l}\text { PR consider that psychopathology is (and should be) a core part of } \\
\text { psychiatric curricula, but are dissatisfied with current training }\end{array}$ & 46 & 1 \\
\hline Fluyau [71] & USA & Systematic review & $\begin{array}{l}\mathrm{DSM} / \mathrm{ICD}, \mathrm{RDoC} \text {, and } \mathrm{DP} \text { : strengths, weaknesses, and the need to } \\
\text { integrate them into teaching and practice to improve patient's well- } \\
\text { being }\end{array}$ & 36 & - \\
\hline Hodes [58] & UK & Curriculum design & $\begin{array}{l}\text { A core curriculum in child and adolescent psychiatry based on } \\
\text { developmental psychopathology: justification, experience, and prospects }\end{array}$ & 37 & - \\
\hline $\begin{array}{l}\text { Houpt et al. [42] } \\
\text { Houpt et al. [43] } \\
\text { Russell et al. [44] }\end{array}$ & USA & $\begin{array}{l}\text { Curriculum design } \\
\text { and reflection }\end{array}$ & $\begin{array}{l}\text { A competency-based model for training in consultation-liaison } \\
\text { psychiatry, setting behavioral objectives in core areas: data gathering } \\
\text { (multiple sources and interviewing), case formulation (synthesize, } \\
\text { design, and write/report), intervention skills, special areas (emphasis in } \\
\text { symptom description and specific psychopathological aspects), and } \\
\text { liaison psychiatry (teamwork). Evaluation is discussed but not } \\
\text { conducted }\end{array}$ & 41.5 & - \\
\hline $\begin{array}{l}\text { Hung and Azzam [45] } \\
\text { James and Hung [46] }\end{array}$ & USA & $\begin{array}{l}\text { Review and } \\
\text { recommendations }\end{array}$ & $\begin{array}{l}\text { Supervision of trainees in the psychiatric emergency service: supervisor's } \\
\text { educational role, models, feedback, barriers, etc. }\end{array}$ & 45 & - \\
\hline Marin et al. [55] & USA & Curriculum design & $\begin{array}{l}\text { Recommendations for educating PR in geropsychiatry and late-life } \\
\text { psychopathology, focusing on the objectives and methods }\end{array}$ & 37.5 & - \\
\hline Nikapota [65] & UK & Review and course & $\begin{array}{l}\text { Acquisition of knowledge and skills in child and adolescent psychiatry } \\
\text { (both psychopathology and management) in a transcultural context }\end{array}$ & 38 & $1,2,4$ \\
\hline Sampogna et al. [73] & Europe & Survey & $\begin{array}{l}\text { Training in psychopathology in Europe is mainly theoretical; PR are } \\
\text { dissatisfied and demand more supervision and time with patients }\end{array}$ & 42.5 & 1 \\
\hline Santos et al. [66] & USA & Review and course & $\begin{array}{l}\text { Training in psychopathology for child and adolescent PR using } \\
\text { problem-based learning as an educational method: review and } \\
\text { implementation }\end{array}$ & 41 & 1,2 \\
\hline Shea et al. [56] & USA & Course & $\begin{array}{l}\text { A training program on interviewing based on individualized educational } \\
\text { goals, a clinical rotation, and group classes: the WPIC experience }\end{array}$ & 43.5 & 1,3 \\
\hline Shea et al. [67] & USA & Review and primer & $\begin{array}{l}17 \text { core principles for designing and implementing interviewing training } \\
\text { programs that include DP, reviewing WPIC and DIMP experiences }\end{array}$ & 45.5 & 1,3 \\
\hline Stein et al. [52] & USA & $\begin{array}{l}\text { Controlled, } \\
\text { nonrandomized trial }\end{array}$ & $\begin{array}{l}\text { PR and supervisors differed regarding psychopathology when the latter } \\
\text { was not present during the patient's interview and agreed when present }\end{array}$ & 41.5 & 3 \\
\hline Taylor and Vaidya [68] & USA & Survey & DP and classical authors are relegated in US residency programs & 36.5 & 1 \\
\hline
\end{tabular}


Table 2 (continued)

\begin{tabular}{|c|c|c|c|c|c|}
\hline Source & Country & Type & Summary & CRAAP & Kirkpatrick \\
\hline Thompson [59] & USA & Curriculum design & $\begin{array}{l}\text { Transcultural curriculum for PR regarding American/Alaskan Natives, } \\
\text { including DP during PGY-1/PGY-2 and expected skills/attitudes }\end{array}$ & 37 & - \\
\hline Tobia et al. [74] & USA & Curriculum design & $\begin{array}{l}\text { After reading/viewing horror artwork, monsters are discussed weekly in } \\
\text { a metaphorical context as psychopathology examples }\end{array}$ & 22.5 & - \\
\hline Valdivieso et al. [75] & Chile & Course & $\begin{array}{l}\text { Teaching DP through clinical cases described by classical authors is } \\
\text { considered by PR interesting and useful for clinical practice }\end{array}$ & 41 & 1,2 \\
\hline $\begin{array}{l}\text { Willmuth and } \\
\text { McKegney [53] }\end{array}$ & USA & $\begin{array}{l}\text { Curriculum design } \\
\text { and experience }\end{array}$ & $\begin{array}{l}\text { A competency-based clinical tutorial for PGY-1, with evaluation and } \\
\text { feedback regarding interviewing and mental state examination, database } \\
\text { collection and recording, and reliability and problem list construction }\end{array}$ & 42 & 1,3 \\
\hline Yates and Gerdes [60] & USA & Course & $\begin{array}{l}\text { PBL in consultation psychiatry: problem identification (such as some } \\
\text { symptoms), literature search/review, and an interdisciplinary discussion }\end{array}$ & 37 & 1 \\
\hline
\end{tabular}

DP, descriptive psychopathology; PGY, postgraduate year; PR, psychiatry resident(s); RDoC, Research Domain Criteria; PBL, problem-based learning.

were of special interest regarding our research question, so we analyzed them in more detail. Based on earlier benchmark systematic reviews in medical education [51], we extracted relevant data (participants, interventions, evaluations, and results) and rated each intervention using the MERSQI scale in order to assess their methodological quality as medical education research pieces.

Both raters scored the sources of our review independently, using the CRAAP test and (when applicable) the MERSQI, and then took the mean value for the table. Before using these instruments in this review, both raters had undergone a preparation stage in order to ensure interrater reliability: first, we had reviewed the characteristics of each tool and discussed every item to clarify their meaning in the scoring schema; second, we practiced in the use of these 2 instruments in selected example articles of a different but related topic (training in psychopharmacology) both independently and together for greater clarification; finally, we both scored the set of sources of this review independently.

\section{Analysis}

We used SPSS 26.0 for Windows (IBM Corp., Armonk, NY, USA) for statistical analysis. For the analysis and interpretation of the data, a biological researcher and lecturer was included to incorporate the view of a nonpsychiatrist who is involved and interested in biosanitary academics but is not familiar with DP.

\section{Results}

\section{Publications about How to Train Psychiatry Residents} in $D P$

The 26 sources are summarized in Table 2 . Sorted by decades, 3 were published in the 1970s (11.5\%) [42-44, $52,53], 3$ in the 1980 s (11.5\%) [54-56], 4 in the 1990 s (15.4\%) [57-60], 8 in the 2000s (30.8\%) [61-68], and 8 in the 2010 s $(30.8 \%)[45,46,69-75]$. As for the country of origin, the USA led with 19 sources (73.1\%), followed by continental Europe with 3 (11.5\%), the UK with 2 (7.7\%), and Canada and Chile with 1 each (3.8\% in both cases).

\section{CRAAP Test}

As for the CRAAP test and the appropriateness of the sources regarding the research question, 3 were excellent (11.5\%), 10 good (38.5\%), 9 average (34.6\%), 3 acceptable (11.5\%), and 1 unacceptable (3.8\%). The mean total score for the whole of the sources was 38.885 (0.983), with a $95 \%$ confidence interval [CI] of 36.859-40.910. We conducted the Shapiro-Wilk test $(p=0.06)$ and concluded that the total CRAAP score did not have a normal distribution.

The raters' CRAAP scores, which can be consulted in full detail in online suppl. Digital Appendix 1 (see www. karger.com/doi/10.1159/000512791 for all online suppl. material), were used to calculate intraclass correlation coefficients (ICC) to determine interrater reliability. The ICC for the total CRAAP score was 0.90 (95\% CI: 0.80$0.96)$.

\section{Kirkpatrick's Levels of Training Evaluation}

Fourteen sources (53.8\%) reported some kind of training evaluation, that is, at least one of Kirkpatrick's 4 levels. Level 1 or reaction was the highest in half of them.

The most frequently reported was level 1 or reaction, which was present in 13 sources $(92.9 \%$ of those that did have some kind of training evaluation and $50.0 \%$ considering all the sources). Level 2 or learning was present in 3 sources $(21.4$, and $11.5 \%$ overall), level 3 or behavior in 4 


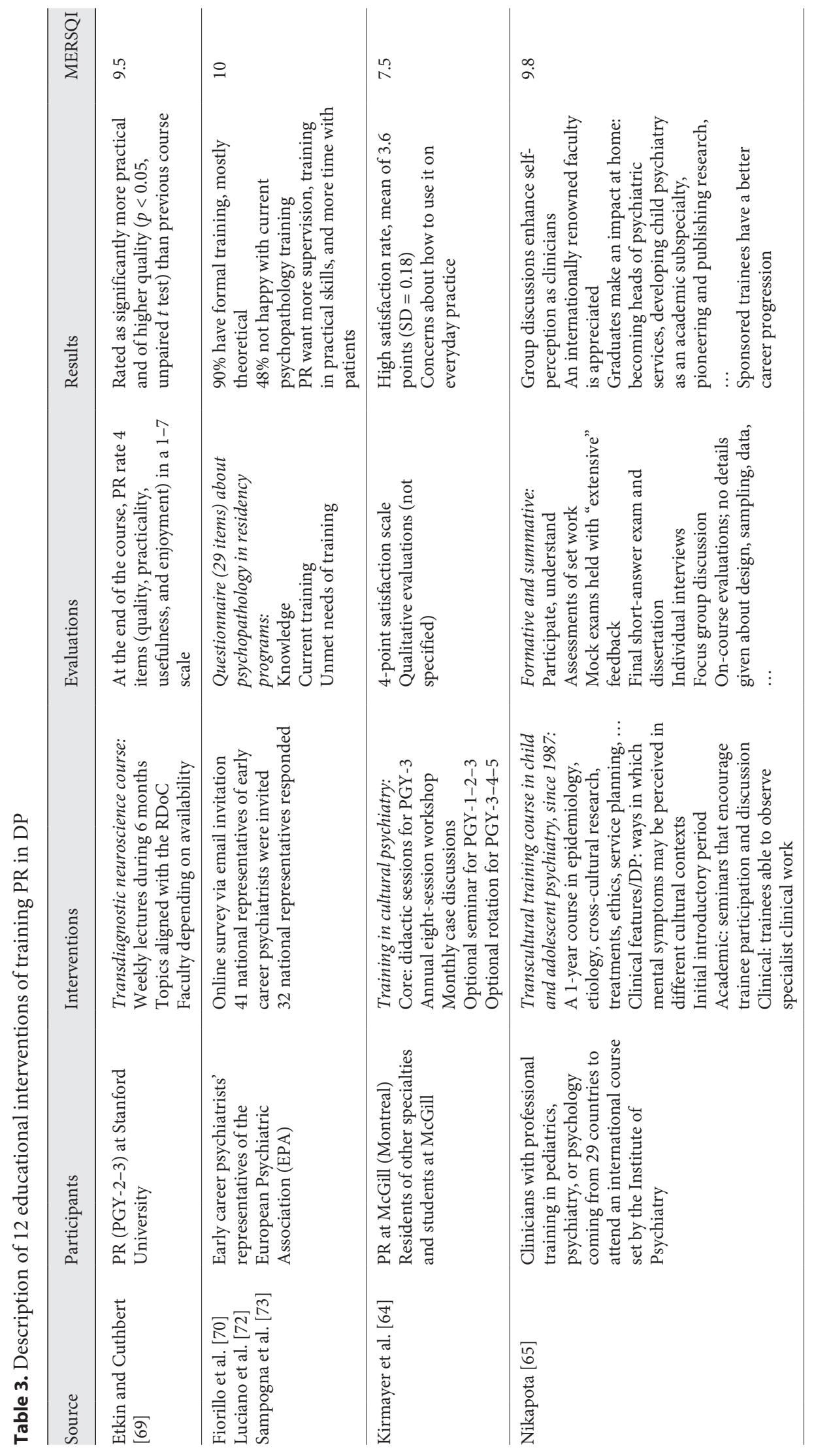




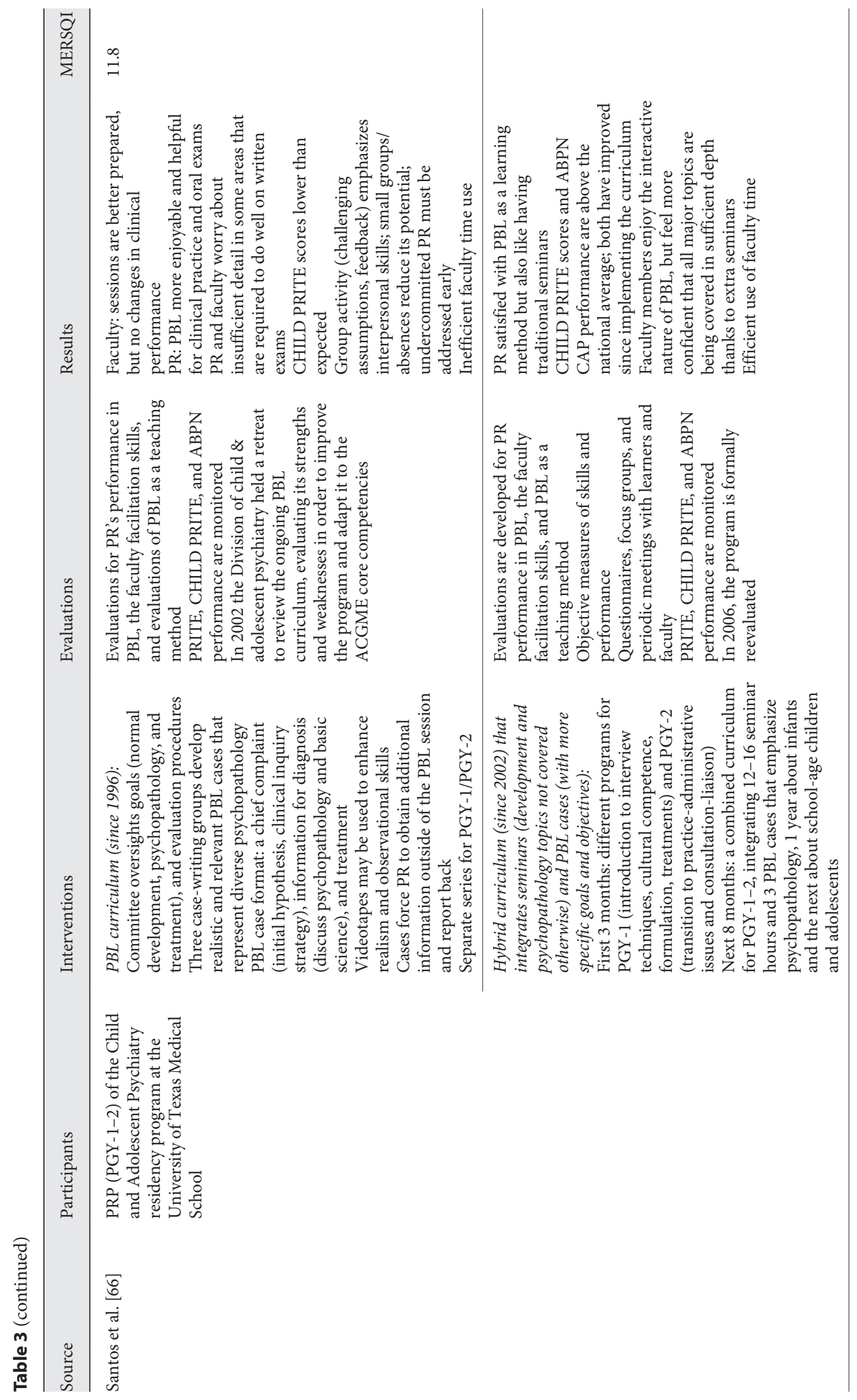




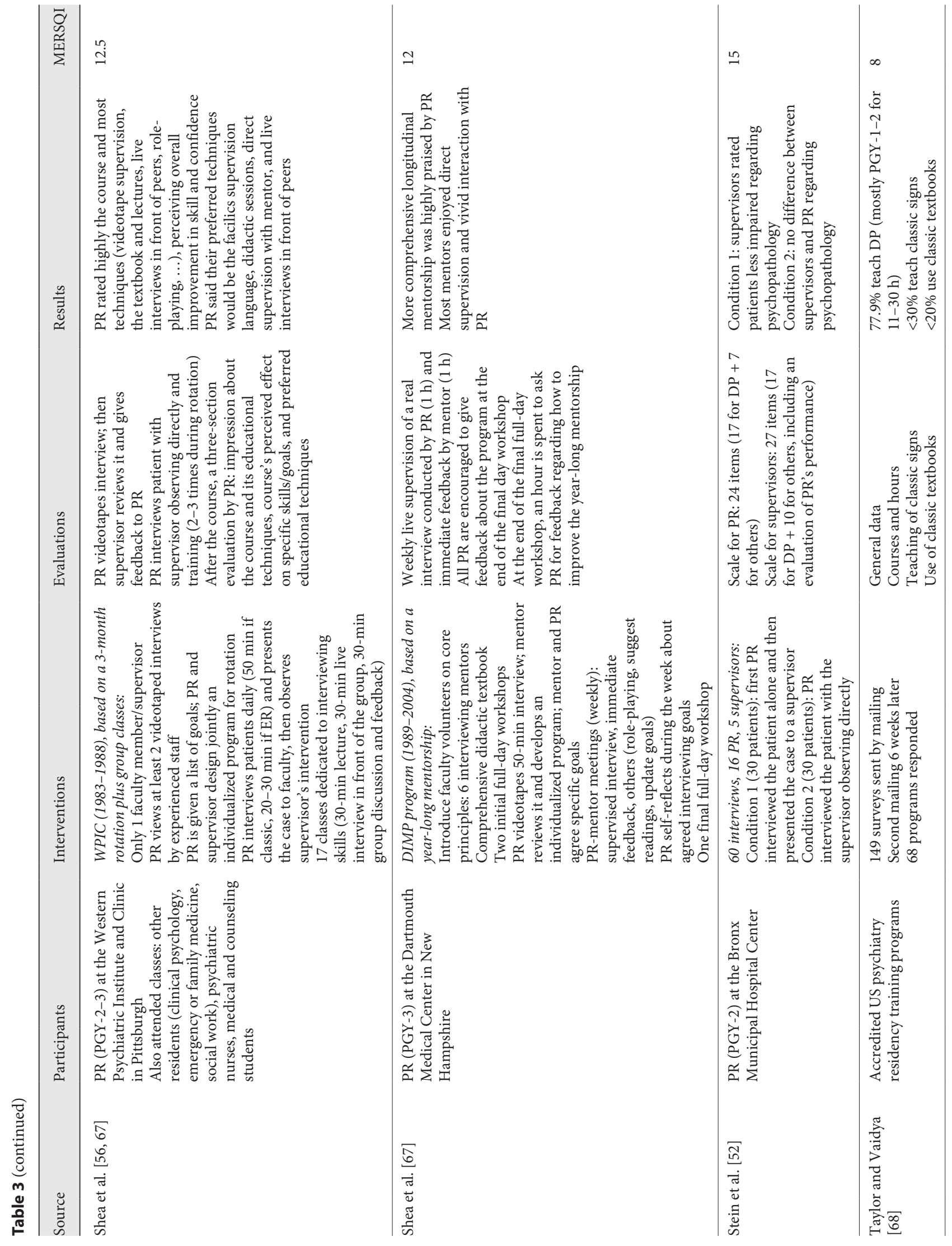




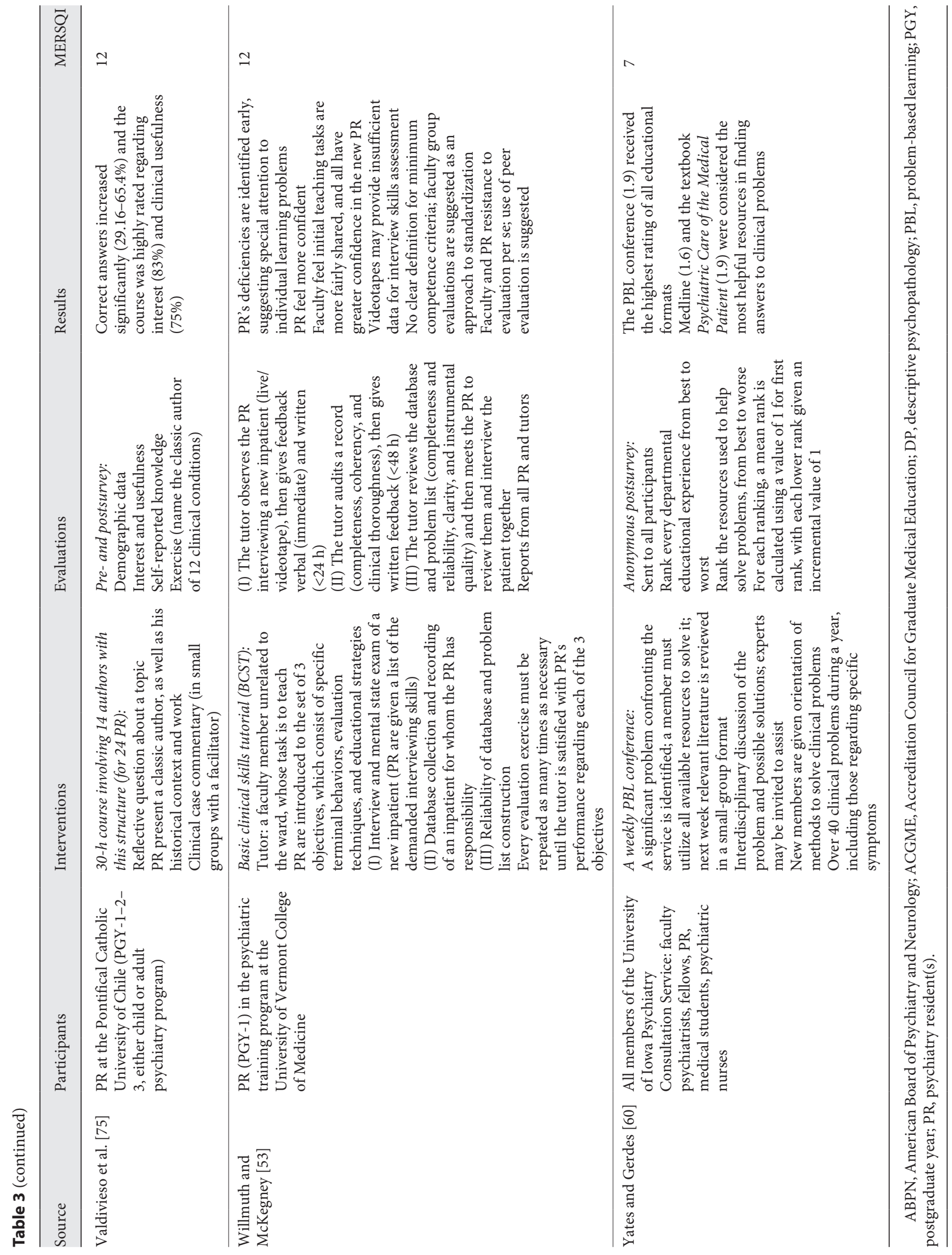


sources (28.6, and $15.4 \%$ overall), and level 4 or results in 1 source (7.1, and $3.8 \%$ overall).

Concerning the 12 sources with no training evaluation, 9 were either designs or proposals ( 7 curriculum designs, plus 1 framework proposal and 1 course design). The remaining were 1 systematic review and 2 literature reviews.

\section{Reported Educational Interventions for Training}

Psychiatry Residents in DP

Out of 14 sources with some kind of training evaluation, 3 sources were in fact describing the same survey $[70,72,73]$; they were thus grouped together, making a total of 12 educational interventions that are analyzed in detail in Table 3. Of them, 8 came from the USA and the rest from Canada, Chile, Europe, and the UK with 1 each.

Besides 2 surveys ( 1 in Europe asking early career psychiatrists and 1 in the USA asking psychiatry residency programs), the other 10 were course or curriculum implementations either for psychiatry residents alone (7) or together with other participants (3); one of them was a controlled, nonrandomized educational trial. Two courses did not detail the participating psychiatry residents' postgraduate year; when specified, PGY-2 psychiatry residents participated in 7 courses, PGY-3 in 4 courses, PGY1 in 3 courses, and PGY-4 and PGY-5 in 1 course that was actually the same.

\section{Educational Methods}

Seminars or didactic sessions made the most widely reported format, as they were present in 8 interventions. Regarding the educational methods, 5 consisted of passive learning through traditional lectures by members of the staff $[56,64-66,69]$. The other 3 involved active learning, as psychiatry residents were requested to search about 1 topic and then report back to the group, usually followed with some discussion $[60,66,75]$. Other reported nonclinical educational methods were case discussion out of clinical setting (4) $[64,66,75]$, annual workshops (2) [64, 67], weekly role-playing (1) [67], generic videos (1) [66], giving an expressly elaborated didactic textbook (1) [67], and suggesting readings (1) [67].

Clinical interviewing with actual patients was reported in 4 interventions [52, 53, 56, 67]. All of them involved the psychiatry resident conducting a live interview with a real patient in the presence of a supervisor, who then gave immediate feedback. Videotaping was also present in 3 of these interventions: the psychiatry resident's interview with a real patient was recorded and then visualized by a supervisor to give deferred feedback; one of them also in- cluded clinical videos by members of the staff as a reference $[56,66,67]$. Other reported clinical educational methods were the tutor/mentor figure (3) $[53,56,67]$ observing a senior psychiatrist's clinical work (2) [56, 65] and reviewing the clinical record elaborated by the resident (1) [53].

\section{MERSQI Score of Methodological Quality}

As for the MERSQI score and the methodological quality of the educational interventions, the mean total score for the whole of them was 10.592 (2.371), with a 95\% CI of 9.085-12.098. We conducted the Shapiro-Wilk test $(p=0.53)$ and concluded that the total MERSQI score did not have a normal distribution.

The raters' MERSQI scores, which can be consulted in full detail in online suppl. Digital Appendix 2, were used to calculate ICC to determine interrater reliability. The ICC for the total MERSQI score was 0.98 (95\% CI: 0.80$0.96)$.

\section{Discussion}

\section{Overall State of the Literature}

This systematic review summarizes available publications in the literature about how to train psychiatry residents in DP. It also summarizes what educational interventions have been reported for training psychiatry residents in DP, as well as the educational methods involved and their results.

\section{Heterogeneity of the Sources}

The heterogeneity of the sources is notable. There are some conceptual differences about what mental symptoms are; this often occurs in the form of implicit assumptions, since the authors rarely explain their framework. Action scopes are equally diverse: either outpatient or inpatient adult psychiatry, child and adolescent psychiatry, consultation-liaison psychiatry, addiction psychiatry, research, etc.

In addition, the role of DP and its training varies from some papers to others: it may be the main focus of the study, it may be integrated into a broader training program that includes nosology and treatment issues, or perhaps the publication may verse about training in some of the constituent components of DP (clinical interviewing and cultural configurators). Transcultural psychiatry has been actively involved in the field of training in cultural configurators, including the efforts of renown groups such as those led by Kirmayer at McGill University and
Etxeandia-Pradera et al. 
Nikapota at the Institute of Psychiatry of King's College, London. This heterogeneity at multiple levels and the fact that some sources treat the issue of training in DP tangentially may explain why the mean CRAAP score (appropriateness regarding the research objectives) was just average.

Lack of Evaluation and the Pending Bridge towards Kirkpatrick's Levels 3-4

It is however the lack of training evaluation that should be the cause for major concern: only half of the sources included some kind of educational assessment, and among those, half reached Kirkpatrick's level 1 only. Without good evaluation of educational efforts, it is difficult to learn what has worked or not worked in DP training. Consequently, there will be little evidence based on best practice that can be disseminated and adapted to improve training worldwide.

Out of 14 sources including some kind of training evaluation, 13 sources (92.9\%) included level 1 and/or level 2 evaluation; only 6 sources (42.9\%) included level 3 or level 4 evaluation. This goes very much in line with the already condemned current overemphasis on levels 1-2 at the expense of levels 3-4, which are precisely more related to the real goals of training: on-the-job application and targeted outcomes in real life. Building a connection bridge between levels 1-2 and levels 3-4 is challenging, yet crucial when conducting training programs and evaluations [33].

In the case of DP, this seems to be especially the case because of epistemological reasons, as mental symptoms are hybrid objects that are co-constructed between the patient and the psychiatrist during the clinical encounter. It would make little sense to assess psychiatry residents only for their knowledge and skills in nonclinical settings, instead of their actual performance with real patients. Use of simulated patients may be suggested as an alternative, but it has intrinsic limitations in psychiatric education, most notably in aspects like empathy and interpersonal relationship [62]. This seems particularly troubling for DP training, as empathy and patient-psychiatrist relationship are essential in the dialogue that eventually leads to symptom formation.

\section{Newer Does Not Mean Better}

Even if over $60 \%$ of the sources included in this review have been published since 2000 , it should be noted that most recent publications are not necessarily better than the old ones. In fact, all 3 sources published in the 1970s were highly rated in the CRAAP test despite being penal- ized by the tool's currency item, thanks to their relevance, accuracy, authority, and purpose. Two of them had a Kirkpatrick's level 3 training evaluation, including the educational intervention with the highest MERSQI score. The third source of the 1970s was a three-part curriculum design for training in consultation-liaison psychiatry that established behavioral objectives in core areas [42-44], very much in tune with current trends in medical education [34].

\section{Recommended Reads When Designing DP Training}

The surveys carried out in Europe and the USA may be useful as a starting point $[68,70]$, although they come up short for more specific guidance. Altogether, because of their appropriateness to the topic and methodological quality, we consider that the core of this review lies in the following works: Santos et al. [66], Shea et al. [56, 67], Stein et al. [52], Valdivieso et al. [75], and Wilmuth and McKegney [53]. They are all educational interventions with some kind of training evaluation, albeit with different characteristics. Thus, depending on each reader's needs and interests, some may be more useful or suitable than others.

On the one hand, studies by Santos et al. [66] and Valdivieso et al. [75] deal with educational interventions in nonclinical settings, thus achieving at most Kirkpatrick's level 2. The former highlights that despite problembased learning being considered engaging, both psychiatry residents and faculty members agreed that theoretical lessons were needed to cover some topics in more depth [66]. The latter consists of a series of seminars with an intriguing synergy between content (classic authors) and form (flipped classroom principles, in which residents play an active role) [75]. We consider these 2 articles of special interest for those who want to start a teaching program in DP at their organization, as training in nonclinical settings is easier to establish and is currently the standard. They could also be useful for those who already have a formal training program in DP at their organization and are willing to introduce new educational methods to make lessons more appealing.

On the other hand, studies by Shea et al. [56], Stein et al. [52], and Wilmuth and McKegney [53] deal with educational interventions in real-life, clinical scenarios [67], thus achieving Kirkpatrick's level 3. All in all, 3 educational methods emerge as crucial for DP training from these 4 works: direct supervision, feedback, and self-reflection. Supervision of the clinical interview with real patients is crucial and must be done in person, with the supervisor present; reviewing the written record should be 
considered, and videotaping can be a good training supplement. Feedback should be given immediately after the interview; it may be extended in writing on a deferred basis. The resident's self-reflection can be complemented by a mentor. Direct supervision, feedback, and self-reflection are along the lines with the demands of psychiatry residents regarding DP training [70]; they also happen to be compatible with competency-based training principles [76]. We therefore consider these 4 works benchmark articles that should be the basis for the design of future interventions, as well as an inspiration for new research projects regarding the training in DP.

\section{Ongoing Challenges and Suggested Topics for Future Research}

The Role of DP within Competency-Based Training

Competency-based training has been formulated as the best approach to the current social and healthcare challenges [34, 77, 78]. Since 2000, several leading countries in medical education have already developed their own versions for competency-based training of various medical specialties such as psychiatry: CanMEDS in Canada, the Accreditation Council for Graduate Medical Education (ACGME) in the USA, Core Psychiatry Training in the UK, etc. In Europe, where significant differences have been reported between countries regarding psychiatry training, the European Union of Medical Specialists (UEMS) also advocates for a common competency-based training and evaluation framework [79].

As the language of psychiatry, DP is essential for any patient-centered care by psychiatrists and should be a core element of competency-based training programs and their evaluation process. However, according to our review, there seems to be no published evidence in peerreviewed journals as to how these ongoing competencybased training frameworks for psychiatry residents are doing on training in DP. Moreover, there is no available literature on how to articulate training in DP within competency-based frameworks, the peculiarities of both DP and competency-based training, and subsequent implications for their association, how to properly integrate DP with the rest of competencies expected in a psychiatrist (e.g., professionalism, communication, and adaptability), etc. This subject may not only be suitable but imperative for future research.

\section{Neglected Contents of DP in Residency Training}

After conducting this systematic review in the available literature on how to train psychiatry residents in DP, we consider that there are a number of neglected contents that represent an opportunity for research. The ostracism of epistemology in DP training is particularly striking, as there are no documented experiences that include it in their teaching programs. The case for a recalibration of language and the need to involve current residents in this process are equally absent.

The conceptualization of mental symptoms as hybrid objects entails reflection on how to design training programs for residents that integrate natural sciences and social sciences. Since psychiatry residents come from medical schools with a background based on the contributions of the natural sciences, training in social sciences (history, sociology, anthropology, etc.) that is appropriate and relevant for psychiatry residents should be incorporated for a proper understanding of DP. Although there has been some initiative in this regard [63], it is still an area for further development.

Introducing the CRAAP Test into Medical Education Reviews

We found the CRAAP test, Kirkpatrick's 4 levels, and the MERSQI to be useful and complementary tools to measure the quality of medical education research. We consider that the CRAAP test allows for evaluation of the appropriateness of a source regarding the research question, something that the other 2 tools fail to do. By ensuring that the raters knew the instruments and were trained in their use, we obtained good interrater reliability for both the CRAAP test and the MERSQI; these tools may be useful in association for future systematic reviews in medical education.

\section{Limitations}

A number of limitations should be acknowledged regarding this systematic review. As for the authors, the BEME Collaboration recommends that the review group has international composition and considers 6-12 members as an optimum number, which was partially the case here as we are a locally established group consisting of 5 psychiatrists and a biologist. Other BEME recommendations about the review group were fulfilled, such as having knowledge of the specific area being reviewed as well as other usually required skills when conducting this type of search [80].

Regarding the inclusion and exclusion criteria, only sources that were either in English or Spanish were included. We took this decision so that all reviewers involved could read and evaluate the sources on their own. We acknowledge the risk of language bias in this regard: at least 1 article with its abstract in English but the manu-
Etxeandia-Pradera et al. 
script in French would have made it to the full-text read phase of the screening process [81].

Data extraction and assessment was conducted by 2 members of the group. It may be argued that these are too few reviewers, especially when using the assessment tools that required scoring. We tried to solve this question by ensuring that both raters had a proper preparation on the use of these instruments and all items had been fully discussed and clarified in advance. We think that the good interrater reliability shows that the approach was valid.

As previously exposed, the CRAAP test has not been used before in the field of medical education systematic reviews to assess the appropriateness of each source regarding the research question. Thus, it is not possible to compare our CRAAP test scores and interrater reliability with those of other groups. Nonetheless, our approach is consistent with BEME recommendations for choosing and implementing a critical appraisal scale in systematic reviews [38]. All in all, we reckon this work as a first approximation that we hope could serve as a stimulus for new contributions and approaches by other authors and, ultimately, for an enriching debate on how to improve training in DP.

\section{Acknowledgements}

The authors would like to thank the staff and trainees at the Psychiatry Service of the Hospital Clínico Universitario de Valencia (HCUV) for their inspiration, as well as Rosa María Pradera Jauregui for her remarks.

\section{Statement of Ethics}

The paper is exempt from ethics committee approval, as it is a systematic review on already available, publicly accessible literature.

\section{Conflict of Interest Statement}

On behalf of all authors, the corresponding author states that there are no conflicts of interest regarding this paper. The authors alone are responsible for the content and writing of the paper.

\section{Funding Sources}

The authors have not received any funding for the present manuscript.

\section{Author Contributions}

The original idea and its development belonged to J.I.E.P. Inclusion and exclusion criteria were set by J.I.E.P. and D.M.U. The search syntax was constructed by D.M.U. and E.J.A., with further assistance by J.I.E.P. The search was conducted by J.I.E.P. and D.M.U. Data extraction and assessment were conducted independently by J.I.E.P. and D.M.U., with further assistance by E.J.A. Statistical analysis was done by F.B.P. and J.C.G.P. As for the discussion, it was coordinated by J.I.E.P. with relevant contributions coming from D.M.U., J.N., and E.J.A. Meanwhile, F.B.P. and J.C.G.P. offered additional points of view.

\section{References}

1 American Psychiatric Association. What is psychiatry? [Internet]. [cited 2019 Aug 11]. Available from: https://www.psychiatry.org/ patients-families/what-is-psychiatry.

2 Berrios GE. The history of descriptive psychopathology. In: Mezzich JE, Jorge MR, Salloum IM, editors. Psychiatric epidemiology: assessment concepts and methods. Baltimore, MD: The Johns Hopkins University Press; 1994. p. 47-68.

3 Berrios GE, Marková IS. Symptoms: historical perspective and effect on diagnosis. In: Blumenfield M, Strain JJ, editors. Psychosomatic medicine. Philadelphia, PA: Lippincott Williams \& Wilkins; 2006. p. 27-38.

4 Berrios GE. The history of mental symptoms: descriptive psychopathology since the nineteenth century. Cambridge, England: Cambridge University Press; 1996.

5 Marková IS, Berrios GE. Epistemology of mental symptoms. Psychopathology. 2009; 42(6):343-9.
6 Berrios GE. History and epistemology of psychopathology. In: Kendler KS, Parnas J, editors. Philosophical issues in psychiatry. III, the nature and sources of historical change. Oxford, England: Oxford University Press; 2015. p. 30-50.

7 Marková IS, Berrios GE. Epistemology of psychiatry. Psychopathology. 2012;45(4): 220-7.

8 Berrios GE. Psychiatry and its objects. Rev Psiquiatr Salud. 2011 Oct;4(4):179-82.

9 Fish F. Fish's clinical psychopathology: signs and symptoms in psychiatry. 2nd ed. Bristol, England: Wright; 1985.

10 Berrios GE, Marková IS. Toward a new epistemology of psychiatry. In: Kirmayer LJ, Lemelson R, Cummings CA, editors. Re-visioning psychiatry: cultural phenomenology, critical neuroscience, and global mental health. Cambridge, England: Cambridge University Press; 2015. p. 41-64.
11 Parnas J, Gallagher S. Phenomenology and the interpretation of psychopathological experience. In: Kirmayer LJ, Lemelson R, Cummings CA, editors. Re-visioning psychiatry: cultural phenomenology, critical neuroscience, and global mental health. Cambridge, England: Cambridge University Press; 2015. p. 65-80.

12 Parnas J, Sass LA, Zahavi D. Rediscovering psychopathology: the epistemology and phenomenology of the psychiatric object. Schizophr Bull. 2013 Mar;39(2):270-7.

13 Parnas J. Foreword. In: Jansson L, Nordgaard J, editors. The psychiatric interview for differential diagnosis. 1st ed. Copenhagen, Denmark: Springer; 2016. p. v-vii.

14 Stanghellini G. Psychopathology: re-humanizing psychiatry. Acta Psychiatr Scand. 2013 Jun;127(6):436-7.

15 Andreasen NC. DSM and the death of phenomenology in America: an example of unintended consequences. Schizophr Bull. 2006 Dec;33(1):108-12. 
16 Rossi A. Psychopathology: education, evidence and translation. the 23rd Congress of the Italian Society of Psychopathology. J Psychopathol. 2019 Mar;25(1):1-2.

17 Insel T, Cuthbert B, Garvey M, Heinssen R, Pine DS, Quinn K, et al. Research Domain Criteria (RdoC): toward a new classification framework for research on mental disorders. Am J Psychiatry. 2010 Jul;167(7):748-51.

18 De Leon J. One hundred years of limited impact of Jaspers' general psychopathology on US psychiatry. J Nerv Ment Dis. 2014;202(2):79-87.

19 De Leon J. DSM-5 and the Research Domain Criteria: 100 years after Jaspers' general psychopathology. Am J Psychiatry. 2014 May; 171(5):492-4.

20 Kirmayer LJ, Crafa D. What kind of science for psychiatry? Front Hum Neurosci. 2014; 8(435):435-12.

21 Lilienfeld SO, Treadway MT. Clashing diagnostic approaches: DSM-ICD versus RdoC. Annu Rev Clin Psychol. 2016;12:435-463.

22 Fuchs T. Ecology of the brain: the phenomenology and biology of the embodied mind. Oxford England: Oxford University Press; 2018.

23 Berrios GE. Towards a new epistemology of psychiatry. Buenos Aires, Argentina: Polemos; 2011.

24 Stanghellini G, Broome MR. Psychopathology as the basic science of psychiatry. Br J Psychiatry. 2014 Sep;205(3):169-70.

25 Volpe U, Sass H. Why, what and how should early career psychiatrists learn about phenomenological psychopathology? In: Fiorillo A, Calliess IT, Sass H, editors. How to succeed in psychiatry: a guide to training and practice. 1 st ed. Chichester, West Sussex: Wiley-Blackwell; 2012. p. 82-97.

26 Stanghellini G, Fiorillo A. Five reasons for teaching psychopathology. World Psychiatry. 2015 Feb;14(1):107-8.

27 Marková IS, Chen E. Rethinking psychopathology. Cham, Switzerland: Springer; 2020.

28 De Leon J. Is psychiatry scientific? A letter to a 21 st century psychiatry resident. Psychiatry Investig. 2013;10(3):205-17.

29 De Leon J. Is it time to awaken sleeping beauty? European psychiatry has been sleeping since 1980. Rev Psiquiatr Salud. 2014;7(4): $186-94$.

30 Morán-Barrios J. Un esid esidentsal para una nueva sociedad. respuestas desde la educación médica: la formación basada en competencias. Rev Asoc Esp Neuropsiquiatr. 2013; 33(118):385-405

31 Wijnen-Meijer M, Burdick W, Alofs L, Burgers $\mathrm{C}$, Ten Cate O. Stages and transitions in medical education around the world: clarifying structures and terminology. Med Teach. 2013;35(4):301-7.

32 Hudziak JJ. Crisis in American psychiatric education: an argument for the inclusion of research training for all psychiatric residents. In: Zorumski CF, Rubin EH, editors. Psychopathology in the genome and neuroscience era. Arlington, VA: American Psychiatric Publishing, Inc.; 2005. p. 203-28,
33 Kirkpatrick JD, Kirkpatrick WK. Kirkpatrick's four levels of training evaluation. Alexandria, VA: ATD Press; 2016.

34 Frenk J, Chen L, Bhutta ZA, Cohen J, Crisp $\mathrm{N}$, Evans T, et al. Health professionals for a new century: transforming education to strengthen health systems in an interdependent world. Lancet. 2010;376(9756):192358.

35 Harden M, Grant J, Buck RG. BEME guide no. 1: best evidence medical education. Med Teach. 1999 Jan;21(6):553-62.

36 Haig A, Dozier M. BEME guide no. 3: systematic searching for evidence in medical education: part 1: sources of information. Med Teach. 2003 Jan;25(4):352-63.

37 Haig A, Dozier M. BEME guide no. 3: systematic searching for evidence in medical education: part 2: constructing searches. Med Teach. 2003 Jan;25(5):463-84.

38 Hammick M, Dornan T, Steinert Y. Conducting a best evidence systematic review. Part 1: from idea to data coding. BEME guide no. 13. Med Teach. 2010 Jan;32(1):3-15.

39 Sharma R, Gordon M, Dharamsi S, Gibbs T. Systematic reviews in medical education: a practical approach: AMEE guide 94. Med Teach. 2015 Feb;37(2):108-24.

40 Liberati A, Altman DG, Tetzlaff J, Mulrow C, Gøtzsche PC, Ioannidis JP, et al. The PRISMA statement for reporting systematic reviews and meta-analyses of studies that evaluate healthcare interventions: explanation and elaboration. BMJ. 2009 Jul;339: b2700.

41 Bramer WM, Rethlefsen ML, Kleijnen J, Franco $\mathrm{OH}$. Optimal database combinations for literature searches in systematic reviews: a prospective exploratory study. Syst Rev. 2017 Dec;6(1):245

42 Houpt JL, Weinstein HM, Russell ML. The application of competency-based education to consultation-liaison psychiatry: I. Data gathering and case formulation. Int $J$ Psychiatry Med. 1977 Dec;7(4):295-307.

43 Houpt JL, Weinstein HM, Russell ML. The application of competency-based education to consultation-liaison psychiatry: II. Intervention knowledge and skills. Int J Psychiatry Med. 1977 Dec;7(4):309-20.

44 Russell ML, Weinstein HM, Houpt JL. The application of competency-based education to consultation-liaison psychiatry: III. Implications. Int J Psychiatry Med. 1977 Dec;7(4): 321-8.

45 Hung E, Azzam A. Supervision of trainees in the psychiatric emergency service. In: Riba $\mathrm{MB}$, Ravindranath $\mathrm{D}$, editors. Clinical manual of emergency psychiatry. Arlington, VA: American Psychiatric Publishing, Inc; 2010. p. 315-47.

46 James M, Hung E. Supervision of trainees in the psychiatric emergency service. In: Riba $\mathrm{MB}$, Ravindranath D, Winder GS, editors. Clinical manual of emergency psychiatry. 2nd ed. Arlington, VA: American Psychiatric Association; 2016. p. 295-326.
47 Sullivan GM. Deconstructing quality in education research. J Grad Med Educ. 2011 Jun; 3(2):121-4.

48 Garcia M, Daugherty C, Ben Khallouq B, Maugans T. Critical assessment of pediatric neurosurgery patient/parent educational information obtained via the internet. J Neurosurg Pediatr. 2018;21(5):535-41.

49 Texas State University Libraries. LibGuides: finding and evaluating web sources: the CRAAP test [Internet]. 2019 [cited 2019 Oct 4]. Available from: https://guides.library.txstate.edu/c.php?g=184587\&p=4604817.

50 Cook DA, Reed DA. Appraising the quality of medical education research methods: the Medical Education Research Study Quality Instrument and the Newcastle-Ottawa Scaleeducation. Acad Med. 2015;90(8):1067-76.

51 Kothari D, Gourevitch MN, Lee JD, Grossman E, Truncali A, Ark TK, et al. Undergraduate medical education in substance abuse: a review of the quality of the literature. Acad Med. 2011 Jan;86(1):98-112.

52 Stein SP, Karasu TB, Charles ES, Buckley PJ. Supervision of the initial interview. a study of two methods. Arch Gen Psychiatry. 1975 Feb; 32(2):265.

53 Willmuth LR, McKegney FP. A basic clinical skills tutorial for first-year psychiatric residents. Acad Psychiatry. 1977;1(2):151-6.

54 Janzen CL, Philips I, Malloy M. Child psychiatry education in early child development: description of a training program. Child Psychiatry Hum Dev. 1981;11(3):158-66.

55 Marin RS, Foster JR, Ford CV, Reifler BV, Reisberg B, Robinowitz CB, et al. A curriculum for education in geriatric psychiatry. Am J Psychiatry. 1988 Jul;145(7):836-43.

56 Shea SC, Mezzich JE, Bohon S, Zeiders A. A comprehensive and individualized psychiatric interviewing training program. Acad Psychiatry. 1989 Jun;13(2):61-72.

57 Halikas JA. Model curriculum for alcohol and drug abuse training and experience during the adult psychiatry residency. Am J Addict. 1992 Jan; 1(3):222-9.

58 Hodes M. A core curriculum for child and adolescent psychiatry. Eur Child Adolesc Psychiatry. 1998 Dec;7(4):250-4.

59 Thompson JW. A curriculum for learning about American Indians and Alaska Natives in psychiatry residency training. Acad Psychiatry. 1996 Mar;20(1):5-14.

60 Yates WR, Gerdes TT. Problem-based learning in consultation psychiatry. Gen Hosp Psychiatry. 1996 May;18(3):139-44

61 Blass DM. A pragmatic approach to teaching psychiatry residents the assessment and treatment of religious patients. Acad Psychiatry. $2007 \mathrm{Feb} ; 31(1): 25-31$.

62 Brenner AM. Uses and limitations of simulated patients in psychiatric education. Acad Psychiatry. 2009 Mar;33(2):112-9.

63 Bromley E, Braslow JT. Teaching critical thinking in psychiatric training: a role for the social sciences. Am J Psychiatry. 2008 Nov; 165(11):1396-401. 
64 Kirmayer LJ, Rousseau C, Guzder J, Jarvis GE. Training clinicians in cultural psychiatry: a Canadian perspective. Acad Psychiatry. 2008 Jul;32(4):313-9.

65 Nikapota A. Transcultural training in child and adolescent psychiatry. In: Garralda ME, Raynaud JP, editors. Culture and conflict in child and adolescent mental health BT: culture and conflict in child and adolescent mental health. Lanham, MD: Jason Aronson; 2008. p. 205-22.

66 Santos CW, Harper A, Saunders AE, Randle SL. Developing a psychopathology curriculum during child and adolescent psychiatry residency training: general principles and a problem-based approach. Child Adolesc Psychiatr Clin N Am. 2007 Jan;16(1):95-110.

67 Shea SC, Green R, Barney C, Cole S, Lapetina G, Baker B. Designing clinical interviewing training courses for psychiatric residents: a practical primer for interviewing mentors. Psychiatr Clin North Am. 2007 Jun;30(2): 283-314.

68 Taylor MA, Vaidya NA. Psychopathology in neuropsychiatry: DSM and beyond. J Neuropsychiatry Clin Neurosci. 2005 May;17(2): 246-9.
69 Etkin A, Cuthbert B. Beyond the DSM: development of a transdiagnostic psychiatric neuroscience course. Acad Psychiatry. 2014 Apr; 38(2):145-50.

70 Fiorillo A, Sampogna G, Del Vecchio V, Luciano M, Ambrosini A, Stanghellini G. Education in psychopathology in Europe: results from a survey in 32 countries. Acad Psychiatry. 2016 Apr; 40(2):242-8.

71 Fluyau D. Integrating DSM/ICD, research domain criteria, and descriptive psychopathology in teaching and practice of psychiatry. Front Psychiatry. 2018 Oct;9(Oct):484.

72 Luciano M, Del Vecchio V, Sampogna G, De Rosa C, Ambrosini A, Fiorillo A, et al. Training in psychopathology in Europe: results from a survey. Eur Psychiatry. 2015;30:676.

73 Sampogna G, Del Vecchio V, Luciano M, De Rosa C, Fiorillo A. Training in psychopathology in Europe: Are we doing well? A survey among early career psychiatrists. J Psychopathol. 2014 Dec;20(4):377-80.

74 Tobia A, Draschil T, Sportelli D, Katsamanis M, Rosenberg S, Williams JM. The horror!: a creative framework for teaching psychopathology via metaphorical analyses of horror films. Acad Psychiatry. 2013 Mar;37(2):131-6.
75 Valdivieso SA, Brockering W, Mejias M, Villarroel L, Maldonado G, Sirhan M. Evaluación de un modelo de enseñanza de la psicopatología para esidents de psiquiatría. ARS Med Rev Cienc Méd. 2016 Feb;40(1):19-27.

76 Lockyer J, Carraccio C, Chan MK, Hart D, Smee S, Touchie C, et al. Core principles of assessment in competency-based medical education. Med Teach. 2017 Jun;39(6):609-16.

77 Frank JR, Snell L, Englander R, Holmboe ES. On behalf of the ICBME collaborators. Implementing competency-based medical education: moving forward. Med Teach. 2017 Jun; 39(6):568-73.

78 WFME. WFME global standards for quality improvement: postgraduate medical education. The 2015 revision. Copenhagen, Denmark: WFME;2015.

79 Etxeandia-Pradera JI, Martinez-Uribe D, Bellver-Pradas F, Gonzalez-Piqueras JC, Aguilar EJ. The challenge of introducing competency-based psychiatry training in Spain. Acad Psychiatry. 2020 Dec;44(6):770-4.

80 BEME. Steps in the review process: forming a review group [Internet]. [cited 2019 Nov 29]. Available from: https://www.bemecollaboration.org/Step+2+Review+Group/.

81 Mombour W. Teaching psychopathology using the AMDP system in postgraduate education. Acta Psychiatr Belg. 1987;87(2):159-64. 